\title{
LA JUSTICIA Y EL EJERCICIO DE LA MEDICINA A FINES DEL SIGLO XIX EN LA PROVINCIA DE BUENOS AIRES
}

\author{
Astrid Dahhur* \\ Pontificia Universidad Católica Argentina \\ - IICS / CONICET \\ $\bowtie$ astridahhur@gmail.com
}

Recibido: 21 de junio de 2020

Aceptado: 2 de septiembre de 2020 DOI: 10.46553/colec.31.2.2020.p13-40

Resumen: El ejercicio de la medicina en la provincia de Buenos Aires ha sido objeto de interés de la Justicia desde hace tiempo. Varias personas fueron acusadas de ejercicio ilegal de la medicina durante el siglo XIX, y los encargados de decidir si debían ser castigados o no eran los jueces. En principio, el propósito de este artículo es analizar las respuestas legales de los acusados para lograr un beneficio de su situación procesal. En segundo lugar, nos centramos en cómo los agentes de la justicia, en este caso los jueces resolvían las acusaciones, especialmente prestando atención a la diferencia entre lo legal y legítimo. Y por último, relacionado con esto, la actuación del resto de las autoridades estatales y médicas ante la presencia de los curanderos ${ }^{*}$.

Palabras claves: curanderismo; ejercicio ilegal de la medicina; justicia; agentes estatales; Buenos Aires; siglo XIX

\footnotetext{
* Profesora y licenciada en Historia por la Universidad Nacional del Centro de la Provincia de Buenos Aires (UNICEN) y Doctora en Historia por la Universidad Católica Argentina. Es alumna del Programa de Pos Graduados de Historia en la UNISINOS. Becaria post-doctoral CONICET. Sus líneas de investigación están relacionadas con la historia de la salud y la enfermedad de mediados del siglo XIX y primeras décadas del siglo XX. Específicamente aborda estudios sobre curanderismo y medicina popular y la contribución de la inmigración europea al patrimonio inmaterial de la salud en la Argentina.
} 


\begin{abstract}
The medical practice in Buenos Aires has been matter of concern of the Justice for a long time. Several people have been accused of practicing medicine without diploma along Nineteenth Century, and judges had to decide if they deserved to be punished or not. First, the aim of this article is to analyze how the folk-healers reacted to the prosecution using legal resources to their own benefit. Second, we focus our interest on the agents of justice and the way they solved the prosecution, specially paying attention to the difference between legal and legitimate actions. And finally, we study the actions of the others authorities to the folk-healer's actions.
\end{abstract}

Keywords: Folk healing; Illegal Medicine Practice; Justice; State Agents; Buenos Aires; Nineteenth Century

\title{
I. Introducción
}

La situación actual de la Argentina y el mundo nos ha llevado a revisar las distintas respuestas que las sociedades dieron a diferentes epidemias a lo largo de los siglos (Álvarez 2020; Agostoni 2020; Johnson-Saletti-Tumas 2020; Testa 2020). Mucho se ha debatido acerca de la aplicación de la cuarentena, el aislamiento de ciudades, barrios y los impedimentos de circulación de las personas en post de preservar la salud y evitar lo más posible la propagación del virus. Los medios de comunicación y las redes han propiciado que la población tenga un acceso casi inmediato a lo que sucede en otras latitudes. En esta cultura de la inmediatez y de las libertades individuales y colectivas el rol del Estado para hacer cumplir la ley y preservar la salud de la mayor cantidad de personas es indispensable. Para muchos esto es una novedad, sin embargo, el rol del Estado en el control de la salud de la población es algo que desde mediados del siglo XIX sucede en la Argentina. Ejemplo de ello son las causas por ejercicio ilegal de la medicina que se hallan en los juzgados del Crimen, en esta ocasión de la Provincia de Buenos Aires.

En provincia de Buenos Aires por ejemplo numerosos estudios han dado cuenta del accionar de del Estado en materia de salud (Biernat 2019; Dahhur 2019; 2020; Calandria 2015; 2017; Calandria y Ledesma Prieto 2018). Un 
recorrido por la historia de la práctica médica realizada por algunos historiadores argentinos (Armus 2000; 2007; Rodríguez Carbonetti y Andreatta 2013; Di Liscia 2002; 2014; Álvarez 2010; Armus 2000; 2007; Armus-Belmartino 2001; Biernat-Cerdá-Ramacciotti 2015; González Leandri 1996; 1999; 2006; 2013, entre otros) revela las distintas etapas que atravesó el proceso de medicalización. Recientemente se definía a la medicalización como la forma en que el ámbito de la medicina moderna se ha expandido y que abarca muchos problemas que antes no estaban considerados como entidades médicas (Márquez y Meneu 2003, 47). El pasaje de consejos o juntas nacionales de sanidad a departamentos nacionales, significó la búsqueda por estructurar organismos ejecutivos capaces de desempeñar acciones rápidas en un campo de creciente interés para las clases dirigentes. Un momento posterior en la organización sanitaria estatal sería representado por la aparición de las direcciones de sanidad, o ministerios que suponían un definitivo reconocimiento a la importancia de la gestión oficial en esta área. Cada una de estas etapas señaló el comienzo de mayor intervención estatal en los asuntos referentes a la salud de la población.

En Argentina, hacia fines del siglo XIX, los médicos buscaban consolidar su poder como únicos depositarios del saber científico; es por ello que apelaron al Estado para alcanzar cierta legitimidad y lograr el monopolio de la profesión. Independientemente del reconocimiento e influencia que supieron lograr en ciertas esferas estatales esto no garantizó una aceptación por parte de toda la población que siguió optando en varias oportunidades por los llamados curanderos, especialmente en las zonas rurales. En este proceso, intentaron afirmarse como los únicos proveedores de los servicios de salud, aumentando en número, creando y fortaleciendo sus instituciones de representación académica y de agremiación, haciendo efectiva su oposición a competidores tales como la medicina casera o los curanderos y ganando la confianza de la gente utilizando los modernos métodos de la publicidad. Por su parte, el Estado apoyó a través de medidas represivas el proyecto de profesionalización y de concentración de atribuciones de los médicos, en la medida que le permitió desarrollar su propia capacidad de intervención social por medio de la asistencia pública de los enfermos, haciéndose cada vez más presente en la regulación de la red de instituciones de atención, tradicionalmente en manos de sociedades 
filantrópicas o asociaciones étnicas, y apostando a la centralización administrativa de las políticas sanitarias (González Leandri 1996; 1999; 2005; 2013; Armus-Belmartino 2001). Esto claro se dio especialmente en las grandes urbes como Buenos Aires, Rosario y Córdoba, en el interior del país la estructura estatal era más endeble (Di Liscia 2010) y la carencia de recursos humanos y económicos dificultaba las tareas al igual que la superposición de funciones (Biernat 2015) de los distintos organismos gubernamentales.

Uno de los obstáculos a este proceso de medicalización fue, sin dudas, la medicina popular y sus agentes. No obstante, las limitaciones presupuestarias del Estado para consolidar su sistema sanitario y la falta de la presencia de médicos diplomados en muchos lugares del territorio nacional, llevaron a un doble discurso por parte de los galenos y de los funcionarios de higiene. De un lado la condena pública de la medicina popular y, de otro, la aceptación tácita de su existencia y el intento de su cooptación como recurso (González Leandri 1996; 1999; 2005; 2013; Armus-Belmartino 2001). Este tipo de personajes y sus prácticas han sido objeto de estudio en varios países como México (Agostoni 1999; 2018) Colombia (Sowell 2002; Valderrama, García y Montoya 2012), Chile (Correa Gomez 2015; 2017), Costa Rica (Palmer 2003) y Brasil (Weber 1999; De Almeida 2018) entre otros países, al igual que en Argentina (Allevi y Carbonetti 2018; Di Liscia 2002; Dahhur 2018; Farberman 2005; 2010; Podgorny 2012; 2015; Rivero, Carbonetti y Rodríguez 2017; Rivero y Vandía 2018; Allevi, Carbonetti y Sedrán 2018). En pos de sumar adeptos a la causa de legitimación de la medicina se iniciaron campañas de desprestigio a las prácticas consideradas no médicas. La persecución de las prácticas de medicina no institucionalizada como así también las creencias consideradas supersticiones desde ciertos sectores ha sido abordada recurrentemente por la historiografía. Un ejemplo de esto son las obras de Juan Pablo Bubello (2012) y Pablo Santos (2008) quienes han tomado a la persecución y condena de prácticas religiosas y curativas a modo de objeto de análisis. En las zonas urbanas, por ejemplo, existían ciertas prácticas que eran condenadas de parte del claustro médico como fueron en principio el mesmerismo, devenido en hipnotismo (Vallejo 2017a; 2017b; 2018), o el espiritismo (Villalba 2017) y la homeopatía finalmente aprobada y reglamentada en la década de 1940 y la magnetoterapia entre otras. 
En este artículo en particular nos centraremos en los intentos por parte del Estado del control del ejercicio de la medicina y cómo en cuatro casos la justicia dependiendo de las circunstancias decidía fallar a favor del acusado o en contra. Podremos así apreciar la distancia entre la norma y la práctica al comparar las resoluciones de los casos con lo señalado por la ley sobre los personajes llamados curanderos. Así, estudiaremos la brecha entre la práctica y la norma que en ocasiones podría ser más amplia de lo esperado por ciertos sectores. Para ello nos servimos de cuatro expedientes judiciales pertenecientes a los Juzgados del Crimen de la Capital y del Sud de la Provincia de Buenos Aires. Visualizaremos también algunas cuestiones políticas, que en ciertos momentos les permitían escapar de ciertas acusaciones. Decidimos emplear solamente estos cuatro expedientes, de un corpus documental de más de 40 casos, pues a través de los testimonios allí preservados es en donde se pueden apreciar más claramente cómo los acusados empleaban los recursos administrativos y judiciales en su favor; como así también las redes de relaciones con personajes del ámbito político de los poblados en donde se hallaban. Es así que nos proponemos mostrar cómo el ejercicio de la ley, de la medicina y las concepciones de la población y agentes judiciales y políticos entraba en tensión con la normativa vigente en el último tercio del siglo XIX. Veremos un equilibrio muy fino entre lo legal y lo legítimo, aquí entran en consideración cuestiones ligadas a la cultura legal y a la cultura judicial (Corva 2014, 28) para poder llevar a cabo la resolución de un caso. Para esto emplearemos dos fondos documentales que han sido escasamente analizados En principio tres expedientes de la Justica del Crimen del Juzgado de la Capital, correspondiente a la ciudad de Buenos Aires y zonas aledañas antes de la federalización de la misma en 1880. Y en segundo lugar el expediente del caso de Gerónimo Solané, el cual debería estar en el Archivo del Departamento Judicial de Dolores, pero sin razón aparente se halla en el Museo Histórico de Fuerte en la Ciudad de Tandil. Dos de los cuatro expedientes tienen la particularidad de haber ocurrido antes de la sanción de la ley de ejercicio de la medicina en la Provincia de Buenos Aires en 1877, sin embargo, al momento de los hechos se encontraba vigente la normativa desde 1870 de los Consejos de Higiene, los cuales eran los encargados de la sanción a aquellos que violasen la ley siempre y cuando no se produjera un 
dolo, ya sea un daño o la muerte de una persona. De ser así se apelaba a la Justicia del Crimen.

El siguiente artículo se encuentra estructurado de la siguiente manera. En primer lugar, contextualizamos el estado sanitario y la conformación de diferentes instituciones, a nivel nacional y provincial, para el control del ejercicio de la medicina, asimismo explicamos las normativas ideadas para el control de la práctica médica. Y finalmente los tres últimos apartados se corresponden a los tres curanderos a analizar en donde empleamos documentación judicial proveniente del Juzgado del Crimen de la Capital (La Plata) y de un Sumario Judicial de la Justicia del Crimen del Sud de la Provincia de Buenos Aires.

\section{Contexto social, económico y jurídico en la Provincia de Buenos Aires}

Durante estos años el descubrimiento de la enfermedad como problema social en Argentina (Armus 2000) fue una suerte de ideología urbana articulada en torno a los temas del progreso, el orden, la multitud, la higiene y el bienestar. Esta ideología, por un lado, ganó terreno en la segunda mitad del siglo XIX y se vinculó a la organización política general, por un lado. Y por otro, a una atención mayor puesta en las enfermedades, sobre todo epidémicas, que asolaron las ciudades y, sobre todo, los puertos. Todo esto se daba durante un proceso general de crecimiento económico y contacto con otras regiones de ultramar. La epidemia de fiebre amarilla, que se inició a principios de 1871 en Buenos Aires, fue decisiva, ya que la altísima mortalidad, la organización de la población y la constitución de un grupo profesional derivaron en una modernización de la infraestructura urbana porteña, incidiendo a su vez en una mayor intervención estatal, por lo menos desde el discurso, en el resto del país. En las áreas rurales estas políticas fueron de ejecución más dificultosa debida cuenta de la dispersión poblacional como así también en algunos casos por la ausencia de médicos diplomados en las zonas. La medicina pasó a ser, junto con la química y la farmacología, una de las ramas científicas de mayor desarrollo a fines del XIX y principios del XX. 
Fue así como también la creación de la Facultad de Ciencias Médicas, el surgimiento de asociaciones médicas y la aparición de la enfermedad como un problema social a ser atendido enmarcan buena parte de lo que desarrollaremos en breve. La medicina académica buscaba hacerse con un halo de respetabilidad y confianza a partir de los adelantos en materia sanitaria, como la higiene. La función principal de los médicos desde mediados del XIX fue intentar cooptar la mayor cantidad de "clientes" de los llamados curanderos. Sin embargo, para ello era imprescindible ganarse el respeto de una profesión que, hasta el surgimiento de la bacteriología en Europa, salvo por el título universitario, no se diferenciaba mucho de quienes pretendían destronar (Di Liscia 2002, 152). Los avances científicos junto con la creación de la Facultad de Ciencias Médicas, el acecho de epidemias y el incremento de médicos en la ciudad y provincia de Buenos Aires dieron lugar a un proceso de medicalización.

Entonces, la medicina, a fines del XIX, era considerada una profesión por lo que se esperaba poder vivir de ella y que sus servicios fuesen abonados en metálico a diferencia de los médicos populares que aceptaban diversas formas de remuneración como contrapartida de sus servicios (Di Liscia 2002, 264). Esta definición colisionaba con la idea de que el curanderismo podía ser una profesión en sí debido a los testimonios de los mismos curanderos. Constan en los testimonios registrados en causas judiciales en el Departamento Judicial de la Capital de la Provincia de Buenos Aires, que los médicos populares aseveraban en la mayoría de los casos no cobrar por su trabajo, pues poseían un "don” que debía ponerse al servicio de los demás.

La situación en el interior de la provincia no era igual que la de la ciudad de Buenos Aires. Allí hallamos sociedades prácticamente rurales que basaban su economía en la explotación agrícola ganadera. Los casos de los curanderos a analizar se suscitaron en un periodo en el cual se dio una expansión de la frontera productiva, como así también un aluvión inmigratorio (Bjerg 2009) debido a las oportunidades laborales generadas por su inserción productiva en el mercado mundial. Buenos Aires así, fue receptora de 30.000 personas en la década de 1870 (Bjerg 2009, 22) que llegaban en busca de trabajo ya fuese desde otras provincias como de ultramar. Esta circulación de personas propició la llegada de saberes curativos desde diferentes regiones al igual que creencias religiosas ligadas 
a ellos. Si bien la mayoría de estas personas se concentraron en los centros urbanos, no tanto en las áreas rurales, las mismas fueron destinatarias de diferentes grupos de extranjeros. Los danenses (Bjerg 2001), españoles (Da Orden 2005) o vascos (Irianni 2000), entre otros son algunas de las muestras de la inmigración en zonas rurales de la provincia de Buenos Aires, españoles e italianos en su mayor parte.

Hacia 1854 con el Código Rural se instaló en la Campaña bonaerense la justicia letrada, que con la creación de jueces de primera instancia instruidos colisionarían en principio sus atribuciones y actividades con los jueces de paz, sin embargo, unos y otros lograrían congeniar a fin de impartir justicia. La justicia letrada fue la institución modernizadora en materia judicial en la provincia de Buenos Aires. Particularmente los juzgados del crimen se encargarían de juzgar y dictaminar penas a los infractores de delitos penales en lugar de los jueces de paz (Seidellán 2012, 45; Yangilevich 2012, 72).

Asimismo, los diferentes grados de conflictividad y criminalidad derivaron en diversas medidas tomadas por el Gobernador Valentín Alsina para garantizar la institucionalidad de la provincia y reducir el poder de los Jueces de Paz instalados durante el rosismo (Yangilevich 2007; Seidellán 2012,36). Estos esfuerzos dieron lugar a la creación de una justicia criminal letrada que con la sanción del Código Rural en 1854 y el Código Penal ambos crearían una red institucional para detener el delito, entre ellos el ejercicio ilegal de la medicina. Los expedientes judiciales con sus limitaciones permiten reconstruir los usos y costumbres de la población y cómo estas colisionaban con las normas. En relación a la práctica de la medicina ilegal contadas son las investigaciones que han empleado este tipo de documentación. Para periodos anteriores los trabajos de Liliana Pizzo (2004) para Córdoba o de Judith Farberman (2005) en Santiago del Estero se utilizaron fuentes en las que las concepciones religiosas de la parte acusadora eran preponderantes pues lo que se perseguía básicamente era a la brujería. Primera gran diferencia, la justicia de fines del siglo XIX y principios del XX era una justicia laica. Esto último no significó que algunos de los argumentos descalificadores hacia los acusados tuviesen similitudes con los esgrimidos por la Iglesia en siglos precedentes. En las Memorias de Gobierno de 1882 una de las obligaciones del Consejo de Higiene Pública, creado en 1870, era salvaguardar la salud de la población mediante el control y la denuncia de aquellos que ejercían la medicina sin titulación y 
hacerles saber de estas irregularidades a los encargados de impartir justicia, ya fuesen los Jueces de Paz o los Jueces del Crimen. En virtud de esto en varias ocasiones otros agentes sanitarios denunciaban lo que ellos veían como irregularidades en el ejercicio de la medicina. La ley sancionada en 1877 especificaba que: "El ejercicio de las profesiones liberales, debe ser reglamentado, restringido y vigilado por las autoridades de cada Provincia". A su vez se especificó que: "nadie podrá ejercer en el territorio de la Provincia, ramo alguno del arte de curar, sin título expedido por la Facultad de Ciencias Médicas, o por los Tribunales que la han precedido" (Registro Oficial 1877, 251-258). Si alguien ejerciese alguna rama de la medicina sin título alguno, sería llamado ante el Consejo para ser apercibido, y si reincidía se lo multaba con la suma de 5,000 \$m/c, por la primera vez, de $10,000 \$ \mathrm{~m} / \mathrm{c}$ por la segunda y de 20,000 por la tercera respectivamente. Finalmente, el artículo 41 concluía que de no satisfacerse la multa o de existir una ulterior reincidencia probada, el Consejo remitiría los antecedentes al Juez del Crimen de turno, quien decidía si lo apresaba o no a razón de un mes por cada 5,000 de multa. Aunque, como señalaremos a continuación, la norma y la práctica se hallaban en algunos casos distanciadas. Un factor que la ley no preveía eran los nexos políticos y las conexiones personales que los infractores a la norma poseían en ciertos poblados.

\section{Curanderos y poder político: EI Tata Dios de Tandil}

Los casos de los tres curanderos que exponemos ahora son un ejemplo de la distancia entre la norma y la práctica que Angélica Corva (2014) ha retratado en su estudio sobre la conformación del sistema judicial bonaerense. El verdadero problema afirma Chartier (2007) es comprender cómo se enlazan las relaciones complejas entre las formas impuestas y las prácticas, algo que realizaremos al analizar el accionar de los agentes de la medicina popular.

El primer caso es el del Tata Dios de Tandil. En 1872 el resonante caso de Gerónimo Solané, alias Tata Dios, dejaba al descubierto la forma en la que el poder político local decidía a quién aplicarle la ley y a quién no. Los mencionados poderes locales se consolidaron con la participación -no 
exentas de pujas- de los vecinos nativos y extranjeros. Los jueces de paz, que detentaron el título de presidentes de las Municipalidades luego de la sanción de la Constitución provincial de 1854, debieron mantener el orden en post del proclamado progreso y por el cual varios de estos agentes se beneficiaron a partir de la expansión económica. El juez de paz detentaba la autoridad civil y era la primera instancia-además de sumariante-en materia judicial en causas leves. De éste dependía la organización de los comicios, los padrones y las levas.

En esta clave se explica por qué el juez de paz de Tandil, Figueroa, no tomó ninguna medida contra Solané por sus actividades, que fueron consideradas por un médico, el Dr. Brid de Azul, como criminales. Figueroa como autoridad municipal tenía el poder de multarlo y encarcelarlo por las denuncias de ejercicio ilegal de la medicina; sin embargo, optó por no hacerlo. El médico denunciaba que en la estancia de Ramón Gómez, cuñado de Juan Figueroa, Solané tenía un "hospital" al que acudían personas enfermas y esto podía derivar en un peligro público. Es por ello que ordenó terminar con las reuniones en la hacienda de su cuñado porque "debía prevenir las consecuencias que pudieran resultar de la aglomeración de gente en la mayor parte enferma" (Libro Copiador del Juez de Paz de 1871, 6 de diciembre de 1871,371$)$ pero no consideraba un delito el accionar de Solané en sí mismo. Aunque, no tomó medidas represoras hasta la masacre tristemente célebre del 1 de enero de 1872. Lo mismo hacía el juez de Azul, quien no consideraba un delito lo hecho por Tata Dios en su jurisdicción:

(...) si esa detención sólo depende de la denuncia del Dr. Brid, sin que haya fundamento serio ni reclamación de parte y sólo por el interés de no consentir de que los que se quieran se hagan curar con el referido curandero, espero que Ud. lo ponga en libertad, recibido que sea la presente, pues durante su administración no está dispuesto a consentir tiranía de ninguna especie. (Santos 1995, 61)

El médico de Policía del pueblo de Azul, Dr. Alejandro Brid había redactado la siguiente queja y denuncia al Comisario Reginaldo Ferreira acerca de las actividades desempeñadas por Tata Dios: 
Un Individuo llamado según me dicen Solano (o Médico Dios) y que vive en el cuartel $7^{\circ}$, a cinco leguas distante de este pueblo, en dirección a Tapalquén, está cometiendo escandalosos abusos, tanto por estar ejercitando la medicina indebidamente cuanto de los medios supersticiosos de que se vale para engañar a personas ignorantes que desgraciadamente es la mayor parte de la que viven en la campaña, haciéndoles creer que es el inspirado de Dios y conversa con él cuantas veces quiere y otras bribonadas por el estilo para expoliarles a mansalva. (Sumario levantado durante la investigación de los asesinatos del 1 de enero de 1872, 21-22)

El Juez de paz del poblado vecino no consideraba que Solané incurriese en ningún delito si ejercía su profesión sin perjudicar a nadie además ejercía una actividad que, en alguna medida, cubría un déficit sanitario. Aquí se aprecia una libertad de acción similar a la del Juez de paz de Tandil, si no hace ningún mal, ¿por qué detenerlo? De acuerdo a sus dichos, el juez no estaba dispuesto a que nadie se comportase como un "tirano" al negarle a otro su trabajo en clara alusión al médico instándolo a que cesara con su hostigamiento. Estas palabras son importantes dado que hablan de una legitimación de su actividad o por lo menos de una utilidad social ante los problemas de la medicina institucional por aquellos años. Solané contaba con el apoyo político de dos de los personajes más preeminentes del poblado de Tandil, mas la participación que se le atribuía como ideólogo de la matanza acaecida el 1 de enero de 1872 impidieron que sus vínculos pudieran hacer algo por él antes de su muerte. Finalmente, Solané se negó a prestar declaración (Dahhur 2012, 154) aduciendo que conocía sus derechos, ante el Juez de Paz y fue asesinado antes de comparecer ante el Juez del Crimen de Dolores. Suerte muy diferente a la de los dos curanderos siguientes.

\section{Los recursos judiciales al servicio de los acusados, el caso Halbout}

Ahora bien, otro caso que supo captar nuestro interés es el de un extranjero, en la localidad de Quilmes en 1876. A diferencia de Solané este personaje no culminó sus días en la cárcel. Al contrario, la información recabada en el expediente permite inferir que el acusado conocía 
plenamente el funcionamiento de los poderes del estado y que supo hacer uso de ellos para su propio beneficio. Una clara diferencia con Solané es que él no recibió un respaldo político de forma obvia, aunque debe haber tenido algunos contactos para poder oficiar su actividad hasta que fue denunciado.

Así fue que Juan Francisco Halbout en la localidad de Quilmes acusó al Juez de Paz de hostigarlo y perseguirlo. El querellante en este caso denunció que el Juez de Paz lo citó para que compareciera ante él y lo acusó de ejercer ilegalmente la medicina por lo que debía pagar una multa de 2000 pesos o en su defecto permanecería arrestado (EXP. 1876-38/333/16 fs.1). Halbout negó las acusaciones y argumentaba que, si hubiese sido cierto, el Juez de Paz no podía condenarlo sin que este se hubiese defendido. Es decir que según sus palabras el Juez cometió una arbitrariedad pues "se encuentra detenido alejado de su familia y negocios siendo la situación perjudicial para sus intereses personales" (EXP. 1876-38/333/16 fs. 1). En su escrito reclamó que su apelación fuera tratada, y que su caso lo llevase el Juzgado de Paz de Barrancas Sud. Incluso con sus palabras deja en claro que conoce por lo menos los engranajes básicos del funcionamiento judicial.

Su moción fue concedida y el Juez del Crimen elevó un pedido de informes sobre la situación de Halbout al Juez de Paz de Quilmes, Felipe Amoedo. En la documentación enviada figuraba con fecha del 18 de febrero de 1876 una nota del presidente del Consejo de Higiene Pública Manuel Porcel de Peralta solicitando la comparecencia ante el Juez de Paz de Juan Francisco Halbout y que le imputase la suma mil pesos por ejercicio ilegal de la medicina. En consecuencia, se lo llamó y estuvo detenido hasta el 22 en que abonó la suma que fue remitida al Consejo de Higiene. Todo esto se debió a la denuncia de Fabián Cueli, Salomé Luque y José Antonio Wilde, doctores en medicina, representados por el Dr. Luque, bajo la acusación de asistencia a enfermos en Quilmes sin tener título, como también contra José Agustín Matienzo (farmacéutico) por la administración que hacía al demandado de las drogas y medicamentos.

Asimismo, el expediente remitido por el Juez de Paz señalaba que Halbout había confesado que "asistía sin exigir retribución alguna" (EXP. 1876-38/333/16 fs.5). Matienzo al comparecer dijo que el acusado había estado ejerciendo indebidamente el oficio de la medicina y la farmacia y tenía conocimiento de que había asistido a un Sr. Cabrera por declaraciones 
de la esposa en presencia de Don José H. Navarro y Antonio Barrera. Resulta que de acuerdo a las declaraciones tomadas a los médicos y a los testigos se llega a la conclusión que Halbout reincidió en la práctica de la medicina por lo que se lo multa con 2000 pesos el 18 de abril de 1876 . En la foja 9 el juez Hudson decide que Halbout sea puesto en libertad acorde al informe del Consejo de Higiene. Aunque al final del expediente con fecha del 2 de mayo se ordenó que se suspendieran todas las causas contra Halbout y que se lo ponga en libertad. La apelación salió en favor del curandero que supo cómo manejar, como veremos al igual que Tagle, los hilos de la justicia y de los poderes locales, rompiendo con la idea de que estas personas no sabían cómo reaccionar ante la justicia y emplear los recursos legales, que la misma ley les daba.

\section{Dos acusaciones y "conspiraciones": Vicente Tagle ante la justicia}

El caso de Vicente Tagle nos permite profundizar sobre cuan complejo era controlar y hacer cumplir la ley de ejercicio de la medicina a fines del siglo XIX en la Argentina. Este es un personaje singular pues hallamos dos denuncias en su contra con pocos días de diferencia en el mismo juzgado por la asistencia a dos personas diferentes. A continuación, veremos cómo las acusaciones y las acciones de los organismos de control fueron una constante a lo largo de los dos expedientes que analizamos.

El 20 de septiembre de 1880 en una carta dirigida a Manuel Porcel Peralta, presidente del Consejo de Higiene Pública (CHP), se le comunicó que Vicente Tagle fue notificado en dos oportunidades por el Juez de Paz de que no estaba autorizado para practicar la medicina. Es decir que recibió dos advertencias por parte de la máxima autoridad del poblado de San Vicente y aun así siguió ejerciendo el cargo sin aparentes represalias. A su vez el mismo médico de la localidad de San Vicente manifestó en el expediente que Tagle se había establecido en el pueblo en donde también ejercía la medicina sin título. En segundo lugar, reiteraba lo que el Juez de Paz Thompson manifestaba, que había sido apercibido en reiteradas oportunidades por pedido del mismo Dr. Felipe Basavillaso en cumplimiento del art. 5 de la ley del 18 de julio de 1877 . Y, en tercer lugar, que, a pesar de las recomendaciones, Tagle ejercía la medicina, sin 
restricción alguna; siendo despachadas sus recetas en las Farmacias de la localidad (Exp. 1880 40-1/352/11 fs.2). Las palabras del médico nos llevan a otro trabajo publicado sobre la temática (Dahhur 2019) respecto de las posturas de los galenos sobre el accionar de los llamados curanderos. Estos mismos al buscar consolidar su poder como únicos agentes legítimos para curar se veían en la necesidad de oficiar de policías e investigadores y denunciar a aquellos que eran su competencia. A su vez hay que recordar que muchas de las técnicas empleadas por los curanderos no diferían de las que los mismos médicos hacían. Los adelantos técnicos y de conocimientos biológicos tendrían su salto de calidad en el siglo XX. Es así que viendo perjudicada su actividad Basavillaso realizó la denuncia contra su contrincante. Sin embargo, esto no redituó en resultados inmediatos; lo único fehaciente fue la elevación del caso al Consejo de Higiene Pública que tenía la facultad de infraccionar, pero no de ejercer el poder de policía, por lo cual era imperante que la justicia fuese involucrada.

A lo largo del expediente el Juez de Paz Thompson se dedicó a tomar declaración a testigos sobre las actividades de Tagle. En este sentido, el 17 de septiembre de 1880 compareció Bonabe Frutos, un argentino, soltero de 25 años al cual le preguntaron qué miembro de su familia había sido asistido por Tagle, a lo cual respondió que "es la mujer que tiene a su lado y otros niños pequeños que también tiene enfermos" (Exp. 1880 40-1/352/11fs.3). $\mathrm{Su}$ nombre era Eulogia Frias y reconoció a Vicente Tagle como el facultativo que la atendió. Este breve pasaje del expediente nos abre una puerta hacia el comportamiento y creencias de la población del interior de la provincia de Buenos Aires. Aun en 1880 con el desarrollo lento pero constante de una corporación médica desde mediados de siglo las personas seguían llamando médicos a aquellos que se ufanaban de poseer conocimientos y dotes para curar o aliviar enfermedades. Frutos, al igual que otros lo consideraba médico, no veía una diferencia entre poseer o no título, el reconocimiento venía por la práctica y no por el estudio.

En el mismo sentido continuaron las testimoniales. El 29 de septiembre prestó declaración Andras Incito un hombre de nacionalidad francesa de sesenta años, cuya esposa había estado gravemente enferma en los primeros días del mes. Él atestiguó que el médico que la asistía era D. Vicente Tagle, (Exp. 1880 40-1/352/11 fs.5). Luego de estos testimonios compareció Vicente Tagle en indagatoria, presentándose como un médico de 37 años, 
italiano. Fue cuestionado sobre si estaba enterado de la prohibición para que practicase la medicina en su contra dictada por el Juez de Paz de la localidad, Felipe Basavillaso; a lo cual respondió que sabía de esa advertencia. Aunque, agregó que a pesar de los apercibimientos continuó prestando sus servicios como médico y que "visto que las mismas autoridades lo autorizaron á tal hecho" (Exp. 1880 40-1/352/11 fs. 6). No queda claro aquí si Tagle se refiere a un recurso excepcional que contemplaba la ley de 1870 que reglamentaba el ejercicio de la medicina. La misma señalaba que las autoridades podían autorizar a personas que carecieran de título o estuvieran en vías de revalidarlo en caso de la inexistencia de facultativos diplomados. Seguidamente en la foja 7 se constató que Tagle ejerció la medicina indebidamente. Por lo tanto, el CHP decide multar a Tagle por reincidencia con 5000 pesos acorde a lo sancionado por la ley del 18 de julio de 1877 art 4. Pero el caso no concluyó aquí pues Tagle interpondría recursos legales para poder revertir la decisión.

Presentó una serie de escritos en la que constantemente hacía notar que el CHP carecía de idoneidad y fundamentos para apercibirlo. Advirtió que la decisión era injusta pues estaba basado en "informes equivocados" y que no estaba dispuesto a que el Consejo lo trate con severidad dado que todo se debía a una "confabulación contraria á la rectitud que esa respetable Corporación debe usar, en todos los casos de esa naturaleza" (Exp. 188040 1/352/11 fs.10). La confabulación claramente se refería a cómo el médico lo había acusado de ejercicio ilegal de la medicina. Finalmente, luego de tres apelaciones el caso queda sin resolución. Algo similar ocurrió con la causa siguiente en la que Tagle era el acusado nuevamente, esta vez por un caso de aborto.

En esta oportunidad la denuncia fue realizada por un farmacéutico, otro agente sanitario, que elevó una nota al presidente del Consejo de Higiene Pública. Allí narró que entre el 6 y 7 de febrero de 1880 desde un partido vecino fue a alojarse a la casa de Don Luis Marcore una joven; la cual requirió los servicios de un médico, Vicente Tagle. De acuerdo a lo informado por el farmacéutico unos días después gracias a algunas preparaciones que le suministró, en particular al uso de "Trocart" la joven abortó. Todo el procedimiento costó 500 pesos. Hasta aquí nada inusual, el comportamiento típico de un charlatán o de un curandero en un poblado del interior de la provincia apuntado por un agente de la salud. Pero lo realmente 
interesante es la acusación lanzada a todo el arco de poder político y médico por el farmacéutico. Lair afirmaba que las máximas autoridades tenían conocimiento sobre las actividades de Tagle en el poblado:

El entonces Juez de paz del partido Sr. Dn. Ángel Plaza Montero, muy ocupado en aquella época con los sucesos políticos, no supo o no pudo dedicar atención al hecho. $2^{\circ} \mathrm{El} \mathrm{Sr}$. D. Adolfo Korn, quien está en poseción (sic) de los datos necesarios.

$3^{\circ} \mathrm{El} \mathrm{Sr}$. Oscar Bergman médico extranjero, residente quien asistió a la enferma desde la salida del Sr. Vicente desde el 27 ó 28 o del mismo mes de febrero, a quien la misma enferma solicitó. (Exp. 1880 40-1/355/2 fs. 2$3)$.

La instrucción continúo y el 20 de septiembre de 1880 el presidente del Consejo de Higiene Pública instruyó al Juez de Paz para que realizara un sumario teniendo en cuenta la "gravedad de los hechos" (Exp. 1880 40$1 / 355 / 2$ fs. 3). Es así que el Juez Thompson le tomó declaración al Dr. Bergman, uno de los mencionados por el farmacéutico Lair. Este galeno de 37 años contestó que atendió al llamado de un médico, Don Vicente Tagle, para asistir a una joven en la casa de Luis Marcore y afirmó que Tagle le había suministrado medicamentos abortivos. Según sus palabras, la joven abortó mientras Tagle la atendía. Se desprende de la declaración del médico algo que podría pasar desapercibido, llamó a Tagle médico, es decir que, en el imaginario de la máxima autoridad médica del poblado, este italiano, carente de titulación era un colega que había incurrido en un delito.

Continúo relatando que cuando fue llamado para brindarle asistencia a la enferma tomó conocimiento sobre el origen del mal por lo que se negó a suministrarle más medicamentos (Exp. 1880 40-1/355/2 fs. 4). En el expediente se dejó plasmado que la joven había desaparecido de la casa paterna y que días después se presentó ante Bergman un deudo de la niña llamándole y pidiéndole que viniese a verla porque se hallaba enferma en la residencia de Marcore, afirmando que se le moría. Manifestó que "la joven (se encontraba) atacada de una fuerte emorragia ( sic) la que ya estaba declinando" (Exp. 1880 40-1/355/2 fs. 4). Cuando se le cuestionó si sabía de situaciones similares, negó saber si Tagle había procedió de igual manera en otros casos. 
Las acciones de Bergmann indicaban que inmiscuirse en el caso podía derivar en una acusación de la mala praxis hacia él, pero lo más destacable es que se negó a prestar ayuda a una convaleciente. Se presenta así una actitud contradictoria en Bergmann quien tampoco denunció la maniobra de Tagle, sino que fue otra persona quien lo hizo, esto solamente fortalece la idea de una connivencia entre algunos médicos diplomados y otros que no poseían título. Incluso podríamos afirmar que los curanderos realizaban las labores que los diplomados se negaban, por una cuestión ética o por miedo a una represalia judicial, o también, atendían a los desahuciados por la medicina oficial. Si a esto se le suma el laxo control en las zonas rurales por parte de las autoridades, los curanderos podían oficiar su actividad sin mayores sobresaltos a menos que alguno de sus pacientes muriera bajo su cuidado.

Seguidamente aparece en la foja 5 la declaración de otro de los mencionados por Lair, Adolfo Korn, ciudadano legal de sesenta años. Acerca del caso le preguntan si tenía conocimiento de los hechos, a lo cual declaró que "había sido voz pública en este Partido pero que él no ha tenido intervención, supo por Bergman que había sido llamado para asistir a una joven que se hallaba enferma en la casa de Marcore, y que cuando este había visto a la joven aquella le había manifestado que Tagle la había hecho abortar." (Exp. 1880 40-1/355/2 fs. 5). Finalmente dijo que había oído que dos o tres más habían sido asistidas por Tagle en abortos, pero "que no ha querido ocuparse de la averiguación de los hechos producidos por Tagle." (Exp. 1880 40-1/355/2 fs. 6). Este testimonio rompe con la imagen del deber ser de los ciudadanos notables de la localidad. Alejandro Korn, en su carácter de ex Juez de Paz, debería haber realizado la denuncia, pero no lo hizo. Fue así que incumplió con su deber, pues al haber aceptado que esta persona ejercía la medicina sin ocultarse debieron tomarse medidas antes del hecho denunciado. Algo no muy diferente de lo ocurrido con Solané y los jueces de paz de Tandil y Azul. Es entonces en dónde el sistema de monitoreo por parte de las autoridades fallaba, ¿o simplemente las leyes lejos de las grandes urbes se relajaban? No existe una respuesta sencilla para esto, es probable que Tagle estuviese amparado por parte del sistema político de la zona, que hubiese forjado una serie de lazos y esto lo beneficiara en su accionar hasta la denuncia de Lair ante el Consejo de Higiene. 
El 29 día de febrero el Juez de paz Thompson mandó a comparecer a Vicente Tagle quien afirmó ser inocente de cualquier cosa y que estaba dispuesto a contestar y dar razones por ese hecho: "por el hecho particular de esa familia que solamente en ese pueblo estaban los asuntos particulares de una familia. (...) Lo que debe demostrar lo demostrará”. (Exp. 1880 40$1 / 355 / 2$ fs. 6). Lo más llamativo fue que afirmó carecer de título al igual que en la causa anterior: "a pesar de no ser recibido lo explicará científicamente" (Exp. 1880 40-1/355/2 fs. 6). Esto quiere decir que aceptaba que la base de su conocimiento era la empiria, lo que no aclaraba si por científicamente se basaba en sus elucubraciones o porque había recibido instrucción universitaria en Italia y no había obtenido su titulación.

Reconoció que fue llamado a la casa de Don Luis Marcone y que también es cierto que asistió a una niña que estaba enferma. Sin embargo, negó que estuviese "en cinta" (Exp. 1880 40-1/355/2 fs. 7). Cuando el Juez de Paz le inquirió que precisara de qué enfermedad se trataba contestó: "Que eso lo dirá ante el Tribunal que deba decirlo." (Exp. 1880 40-1/355/2 fs. 7). Palabras que son similares a las del Tata Dios del Tandil de $1872^{1}$ (Dahhur 2013; Nario 1976) cuando le preguntaron si estando en tratamiento abortó respondió que si no estaba en cinta no podía abortar. En su declaración en esta causa aceptó carecer de título (un delito si no contaba con la autorización de alguna autoridad), aunque, en la anterior aclaró que contaba con un permiso expedido para poder desarrollar la práctica médica, empero no consta en ninguno de los expedientes quién lo apoyaba en su comportamiento.

Ante los dichos del acusado el juez del crimen, Adolfo Insiarte, emitió la orden para que el Dr. Bergman emitiera un certificado médico legal que refrendara el aborto. El 14 de octubre el Dr. Bergman elevó una misiva para certificar sus dichos y el aborto a la joven. A su vez amplió su testimonio al relatar que:

al fin del año proximo pasado se me presentó un individuo, que se dijo ubicado en el partido de Brandzen, pidiendome remedios para una joven,

\footnotetext{
${ }^{1}$ Solané se negó a prestar declaración ante el Juez de Paz de Tandil argumentando que sólo lo haría ante el Juez del Crimen de Dolores. Empero fue asesinado unos días antes de comparecer en su celda.
} 
que se encontraba en cinta... le contesté negativo... por segunda vez aparece en mi casa en el mes de Febrero de este año. Ahora me rogó ir a ver á la misma joven que según él se encontraba muy enferma en San Vicente y en la casa del Sr. Marconi. (...) la joven enferma declaraba haber tenido un 'abundante flujo desangre' que ya se habia parado y que el Dr. Tagle la había asistido hace bastante. Viendo a la joven en cuestión, cuyo nombre por olvido ignoro, por el momento sin peligro, en manos de un médico de la localidad y deseando tener mi reputación limpia en este para mi tan sospechoso asunto, me despedí de la joven sin toda averiguación y por consiguiente me encuentro en este momento inhabilitado para dar un exacto informe médico legal. (Exp. 1880 40-1/355/2 fs. 14).

El 7 de noviembre Tagle declaró que "ofició la medicina hasta que le prohibió el Consejo siendo médico italiano domiciliado en el Partido de San Vicente." (Exp. 1880 40-1/355/2 fs. 16). Sobre el hecho que se le imputó contestó "que al respecto tiene presentada una elevación ante el Juez de Paz" y que asistió de flujos blancos á Marcelina Ruiz que vivía en Brandsen. Los medicamentos suministrados fueron los indicados para esa enfermedad; y que fueron expedidos por el boticario que estaba en San Vicente pagados por el mismo Marcone. (Exp. 1880 40-1/355/2 fs. 16).

Debido a estas declaraciones el 15 de noviembre Marcone fue convocado por la justicia. Declaró que todas las recetas las despachó el boticario Lair, el denunciante. Este último, recién pudo declarar el 24 de enero de 1881 ante el Juez de Paz de Baradero, pues por enfermedad de su esposa y por no contar quien atendiera la botica no podía ausentarse. Explicó que, en los primeros días de marzo de 1880, fue a su casa en San Vicente Don Adolfo Korn, en ese momento Juez de Paz, llevando una carta que pensaba dirigir al "curandero Vicente Tagle" en la cual lo trataba de 'miserable abortador', (Exp. $188040-1 / 355 / 2$ fs. 24), y que la había mostrado el señor Korn a varias otras personas. En ese momento le informó a Korn que la niña estaba embarazada al llegar al poblado. En principio la joven se había dirigido a Don Oscar Bergman en Doncelar para ver si podía practicarle un aborto, pero él se negó terminantemente. Es así que, al arribar a San Vicente llamó a Tagle, y éste la asistió desde el ocho de febrero hasta el veinte y siete del mismo mes. El diagnóstico esgrimido por Tagle al realizar las recetas que mandaba a comprar en la botica de Lair era una pérdida de sangre. 
Posteriormente Korn le informó a Lair que Tagle había hecho uso para "la cura" del trocart y de la Salvia, pero la salvia no fue llevada de la botica. Posteriormente, la niña muy enferma fue otra vez a ver al Señor Bergman en Doncelar y fue ella misma quien le dijo el modo empleado por Tagle para lograr su objetivo. Finalmente, el declarante señaló que, antes de denunciar el hecho al Consejo de Higiene, se lo comunicó a los Señores Korn y Bergmman quienes le ratificaron todo; pero no expresaron ninguna voluntad de denunciar el accionar de Tagle. Aparentemente este personaje era amparado por el poder local posiblemente por haberlos ayudado en ciertas circunstancias o por ser poseedor de cierto tipo de información de índole personal que pudiera perjurdicarlos.

\section{Conclusión}

...el individuo que se hace curar como quiera, tomando los remedios que le parezca, no hace mal a nadie, sino usa de un derecho o de una libertad que ninguna ley escrita tiene el deber de privarle. La prueba está en que, a pesar de todos los reglamentos y las penas establecidas por el Consejo de Higiene, a pesar de la vigilancia que se despliega para evitarla, esa libertad existe, y existen los curanderos por más que se persiguen. Tan es así que de tiempo en tiempo el mismo Consejo de Higiene nos hace saber que existen una porción de personas que viven de curar. Y la razón es muy sencilla: porque es imposible que la autoridad pueda seguir en sus actos a un individuo hasta la cabecera de su cama para privarle en las horas solitarias y en el silencio de su hogar, que no tomen los remedios que suministran los curanderos. (Corva 2014, 248)

Esta cita que María Angélica Corva transcribe del diputado Garrigós durante los debates de la Convención Constituyente Buenos Aires en 1873 es más que acertada para entender la situación reinante en la provincia acerca del ejercicio de la medicina. En los tres casos presentados, Tagle, Halbout y Solané dejan al descubierto los grises que se daban en la aplicación de las leyes que regulaban el arte de curar. En principio lo que pudimos demostrar a través de la documentación judicial que en varias oportunidades los agentes del estado que debían regular y sancionar a 
quienes infringían la ley eran los primeros en mirar hacia un costado. Esto mismo se pudo apreciar con Tagle y Solané que fueron respaldados por autoridades locales y personajes ilustres de las sociedades en donde desarrollaban su actividad.

Las razones de ellas pueden ser variadas. Desde culturales al considerar que no existían diferencias entre quien sabe curar por haber estudiado en una universidad y quien lo adquirió por la experiencia. Connivencia económica, lo que hoy en día sería denominado corrupción (cuestión que no es mencionada en los expedientes trabajados). Falta de recursos para llevar a cabo las investigaciones como así también escasa información sobre lo que sucedía hacia el interior de la provincia. A diferencia de lo que sucedía en las grandes urbes estos personajes muchas veces formaban parte de la comunidad a la que atendían, y los diplomados, en cambio, eran los foráneos y a los que la población veía con suspicacia. Pero tampoco debemos olvidar que en reiteradas oportunidades en el interior rural los llamados curanderos eran los únicos que podían dispensar algún tipo de ayuda en materia sanitaria.

Es decir que la aplicación de las leyes y su consecuente castigo podían variar de acuerdo a las circunstancias en las que se daban los casos de ejercicio ilegal de la medicina. Los agentes del estado, en particular los Jueces de Paz y del Crimen podían llegar a considerar a un acusado inocente simplemente por el hecho de que prestaban un servicio sin recibir ninguna retribución o porque consideraban que no obraban de mala fe. En este artículo lo que buscamos reflejar es cómo la aplicación de las normativas en materia sanitaria podía variar sustantivamente de acuerdo a los casos y a las personas que los juzgaban. Asimismo, destacamos cómo esas personas tildadas de "ignorantes" por la bibliografía médica de la época, nos referimos a los curanderos, tenían en ciertas ocasiones conocimientos cabales sobre los mecanismos legales que podían ayudarlos a evitar una condena, ya fuese porque la causa se dilatara demasiado o porque encontraban alguna falencia durante el proceso criminal. Esto último merecería un estudio más amplio en otros fondos documentales, ya sea de la provincia de Buenos Aires o del resto de la Argentina. Pero deja abierta la inquietud sobre qué tipo de personajes eran estos curanderos y cómo se movían entre la legalidad y la ilegalidad enarbolando su conocimiento, y en 
consecuencia la aplicación del mismo, con una legitimidad que no tenía nada que ver con la sancionada por las leyes.

\section{Referencias}

Agostoni, C. 1999. "Médicos científicos y médicos ilícitos en la ciudad de México durante el Porfiriato." Estudios de historia moderna y contemporánea de México 19 (019): 13-31.

— 2018. "Ofertas médicas, curanderos y la opinión pública: el Niño Fidencio en el México posrevolucionario." Anuario Colombiano de Historia Social y de la Cultura 45 (1): 215-243.

- 2020. "Médicos, enfermeras y pacientes: entre la incertidumbre y las carencias en tiempo de COVID-19 en México". Disponible en: http://www.revistahcsm.coc.fiocruz.br/english/medicos-enfermeras-ypacientes-entre-la-incertidumbre-y-las-carencias-en-tiempo-de-covid19-en-

mexico/?fbclid=IwAR2B0uNAcuCRltL3AHf0xZco2G7fDaSbRmvg2O Vd1fu2HFR9mayN9UN0IX0

Álvarez, A. 2020. "La Historia del COVID 19 en tiempos del Coronavirus. Un ensayo inconcluso". Revista Pasado Abierto 6 (11). Disponible en: https://fh.mdp.edu.ar/revistas/index.php/pasadoabierto/article/view/421 5

2010. Entre muerte y mosquitos: el regreso de las plagas en la Argentina (siglos XIX y XX). Buenos Aires: Biblos.

Allevi, J. I. y A. Carbonetti. 2019. "Peticiones y prerrogativas Médicos y boticarios en la corporativización del arte de curar y la conformación del Estado provincial en Santa Fe, Argentina (1857-1903)”. Varia Historia 35(69): 753-786.

Allevi, J. I., A. Carbonetti y P. Sedrán. 2018. "Médicos, administradores y curanderos. Tensiones y conflictos al interior del arte de curar diplomado en la provincia de Santa Fe, Argentina (1861-1902)". Anuario de Estudios Americanos 75 (1): 295-322.

Armus, D. 2000. "El descubrimiento de la enfermedad como problema social”. Nueva Historia Argentina. El progreso, la modernización y sus límites (1880-1916) Vol. 5, págs. 507-561. Buenos Aires: Sudamericana. 
2007. La ciudad impura: salud, tuberculosis y cultura en Buenos Aires, 1870-1950. Buenos Aires: Edhasa.

Armus, D. y S. Belmartino. 2001. "Enfermedades, médicos y cultura higiénica". Nueva Historia Argentina. Crisis económica, avance del Estado e incertidumbre politica (1930- 1943) Vol. 7, págs. 283-329. Buenos Aires: Sudamericana.

Dahhur, A. 2013. "Ataques a curanderos. La medicina y su lucha por el control social de la población en los primeros años del siglo XX." XIV Jornadas Interescuelas/Departamentos de Historia. Departamento de Historia de la Facultad de Filosofia y Letras. Universidad Nacional de Cuyo.

Biernat, C. 2019. "Jueces, médicos y enfermos. Prácticas y sentidos en la construcción social del delito de contagio venéreo en la Argentina durante la primera mitad del siglo XX". História (São Paulo) 38.

Biernat, C., J. M. Cerdá y K. Ramacciotti. 2015. La salud pública y la enfermería en la Argentina. Bernal: UNQ.

Bjerg, M. M. 2001. Entre Sofie y Tovelille: una historia de los inmigrantes daneses en la Argentina, 1848-1930. Vol. 3. Buenos Aires: Editorial Biblos.

2009. Historias de la Inmigración en la Argentina. Buenos Aires: Edhasa.

Bubello, J, P. 2010. Historia del esoterismo en la Argentina. Buenos Aires: Biblos.

Calandria, S. 2015. "Maternidades en cuestión: modelos idílicos y prácticas de las madres en Argentina 1892-1936." Trabajos y comunicaciones 41. . 2017. "Madres criminales: aportes sobre el infanticidio y la criminalidad femenina bonaerense en clave sociodemográfica." Población \& Sociedad 24 (2).

Calandria, S. y N. Prietto. 2018. "Abortos e Infanticidios: Tensiones y debates en la legislación penal moderna (1886-1968)." Avances del Cesor 15 (19): 101-128.

Correa Gómez, M. J. 2015. "Por haber sanado a muchos y haber matado a varios. Charlatanes, practicantes y curanderos. La Justicia y el ejercicio médico ilegal. Chile, 1874-1919". Delincuentes, policías y justicias. América Latina, siglos XIX y XX (466-490). Santiago: Ediciones Universidad Alberto Hurtado. 
. 2017. "Quiénes son los profesionales? Justicia, profesionalización y ejercicio médico en el Chile urbano de la segunda mitad del siglo XIX”. Dynamis 37 (2): 273-293.

Corva, M. A. 2014. Constituir el gobierno, afianzar la justicia. Rosario, Prohistoria.

Chartier, R. 2007. La historia o la lectura del tiempo. Barcelona: Editorial Gedisa.

Da Orden, M. L. 2005. Inmigración española, familia y movilidad social en la Argentina moderna: una mirada desde Mar del Plata (1890-1930). Buenos Aires: Editorial Biblos.

Dahhur, A. 2018. "Las causas del curanderismo según la prensa en Tandil y en Buenos Aires a principios del siglo XX." Question 1 (59): 1-19.

. 2012. De médicos, poetas y locos todos tenemos un poco. Tata Dios, de santo a asesino. Un estudio de caso sobre el curanderismo en las postrimerías del siglo XIX en El Tandil. Tesis de licenciatura en Historia, Facultad de Ciencias Humanas, UNICEN.

2019. "La medicina popular a través de las fuentes judiciales. El proceso de medicalización en la provincia de Buenos Aires a fines del siglo XIX y mediados del siglo XX.” el@ tina. Revista electrónica de estudios latinoamericanos: 17-66.

—. 2020. “¿Negocio o ayuda al prójimo en la salud?: Una aproximación a la atención de los partos a través de las fuentes judiciales a principios del siglo XX en la Provincia de Buenos Aires." Trabajos y comunicaciones 51.

De Almeida, D. H. 2018. Nós aquí cura com benzedura e raíz de pau. Experiências de curas a partir da cultura popular brasilera e portuguesa (século XX). Tesis de doctorado, Casa de Oswaldo Cruz-Fiocruz, Río de Janeiro.

Di Liscia, M. S. 2002. Saberes, terapias y prácticas médicas en Argentina (1750-1910) (No. 24). Editorial CSIC-CSIC Press

—. 2010. 'Instituciones 'portátiles'. La sanidad Pública en los Territorios Nacionales (1880-1910)". En Un Estado con rostro humano. Funcionarios e instituciones estatales en Argentina (desde 1880 a la actualidad), editado por E. Bohoslavsky y G. Soprano, págs. 359-386. Buenos Aires: Universidad Nacional de General Sarmiento / Prometeo libros. 
2014. "Renovación de la historia sobre instituciones, profesiones y salud". En Historia de la salud y la enfermedad: bajo la lupa de las ciencias sociales, editado por C. Biernat y K. Ramacciotti, págs. 117130. Buenos Aires: Biblos.

Farberman, J. 2005. Las Salamancas de Lorenza, magia hechicería y curanderismo en el Tucumán colonial. Buenos Aires: Siglo XXI editores.

2010. Magia, brujería y cultura popular. De la Colonia al siglo $X X$. Buenos Aires: Sudamericana.

González Leandri, R. 1996. "La profesión médica en Buenos Aires, 18521870." En Política, médicos y enfermedades. Lecturas de historia de la salud en la Argentina, editado por M. Lobato, págs. 21-56. Buenos Aires: Biblos.

- 1999. Curar, persuadir, gobernar: la construcción histórica de la profesión médica en Buenos Aires, 1852-1886. Madrid: Editorial CSICCSIC Press.

- 2005. "Madurez y poder: médicos e instituciones sanitarias en la Argentina a fines del siglo XIX”. Entrepasados 14 (27): 133-150.

—. 2006. "La consolidación de una inteligentzia médico profesional en Argentina: 1880-1900." Diálogos Revista Electrónica de Historia 7 (1): 36-78.

- 2013. "Internacionalidad, higiene y cuestión social en Buenos Aires (1850-1910). Tres momentos históricos." Revista de Indias 73 (257): 23-54.

Irianni, M. 2000. “Inmigrantes vascos tras el mostrador. ¿Audacia o lógica en la pampa argentina durante el siglo XIX?" Studi Emigrazione 138: 431-451.

Johnson, M. C., L. Saletti-Cuesta y N. Tumas. 2020. "Emociones, preocupaciones y reflexiones frente a la pandemia del COVID-19 en Argentina". Ciência \& Saúde Coletiva 25 (1): 2447-2456. Disponible en: $\quad$ https://www.scielo.br/pdf/csc/v25s1/1413-8123-csc-25-s12447.pdf? fbclid=IwAR10ano43gOgFSh6AJiBdznkrsHB7bTbOJDCJjG -GEE4dDivR6jNWAmudvM

Márquez, S. y R. Meneu. 2003. "La medicalización de la vida y sus protagonistas". Gestión clínica y sanitaria 5 (2): 47-53. 
Nario, H. 1976. Tata Dios: El Mesías de la última montonera. Buenos Aires: Plus Ultra.

Palmer, S. 2003. From Popular Medicine to Medical Populism: Doctors, Healers, and Public Power in Costa Rica, 1800-1940. Durham, NC: Duke University Press.

Pizzo, E. L. 2004. Mujeres y poder informal. Salud-enfermedad y hechicería en la Córdoba del siglo XVIII. Córdoba: Editorial Universitas.

Podgorny, I. 2012. Charlatanes, Crónicas de remedios incurables. Buenos Aires: Eterna Cadencia.

- 2015. Charlatanería y cultura cientifica en el siglo XIX. Madrid: Catarata.

Rivero, M, D. y L. Vanadía. 2018. "En los márgenes de la biomedicina: perspectivas en torno a la práctica ilegal de la medicina en Córdoba y Buenos Aires, 1920-1930". Trashumante: Revista Americana de Historia Social 11: 98-121.

Rivero, M. D., A. Carbonetti y M. L. Rodríguez. 2017. “Alternativas al saber diplomado en la escena pública: una aproximación al curanderismo a partir de la prensa escrita de las ciudades de Córdoba y de Buenos Aires, Argentina en la década de 1920". Revista Historia y Sociedad 33: 19-43.

Rodríguez, M, L., A. Carbonetti y M. M. Andreatta. 2013. "Prácticas empíricas y medicina académica en Argentina. Aproximaciones para un análisis cuanticualitativo del Primer Censo Nacional (1869)." Historia Crítica 49: 81-108.

Santos, J. J. 1995. Una revuelta rural en la frontera Sur bonaerense: Tandil 1872. Tesis de licenciatura, Facultad de Filosofía y Letras, UBA.

- 2008. El tata Dios: Milenarismo y xenofobia en las pampas. Buenos Aires: Sudamericana.

Sedeillán, G. 2012. La Justicia penal en la provincia de Buenos Aires. Instituciones, Prácticas y codificación del derecho (1877-1906). Buenos Aires: Biblos.

Sowell, D. 2002. "Andanzas de un curandero en Colombia: Miguel Perdomo Neira". En Entre médicos y curanderos: cultura, historia y enfermedad en la América Latina moderna, editado por D. Armus, págs. 71-103. Buenos Aires: Grupo Editorial Norma. 
Testa, D. 2020. "Cuando lo esencial se hace visible. Reflexiones sobre la pandemia de COVID19 en Argentina." Revista Temáticas. UNICAMP. En prensa.

Valderrama, J. M., V. M. García y P. Del Valle Montoya. 2012. "La profesión médica y el charlatanismo en Colombia en el cambio del siglo XIX al XX.” Quipu 14 (3): 331-362.

Vallejo, M. 2014. "Buenos Aires mesmérica. Hipnosis y magnetismo en la cultura y la ciencia de la capital argentina (1870-1900)". Iberoamericana: 7-26.

2017a. El conde de Das en Buenos Aires 1892-1893. Hipnosis, teosofia y curanderismo detrás del Instituto Psicológico Argentino. Buenos Aires: Biblos.

— . 2017b. "El papel de la prensa en la lucha contra la consolidación de la profesión médica en Buenos Aires, 1890-1900". Dynamis 37 (2): 295-316.

- 2018. "El Instituto Psicológico Argentino (1892). Teosofía, hipnosis y charlatanería en los orígenes de una iniciativa olvidada." Asclepio 70 (1): 217-230.

Villalba, M. 2017. “Juan José Durandó y la Colonia San José (1887-1916) Espiritismo y curanderismo en Entre Ríos". En Estudios sobre la historia del esoterismo occidental en América Latina. Enfoques, aportes, problemas y debates, editado por J. P. Bubello, J. R. Chaves y F. de Mendonça Júnior, págs. 97-128. Buenos Aires: Editorial de la Facultad de Filosofía y Letras, Universidad de Buenos Aires.

Weber, B, T. 1999. "As artes de curar: medicina, religiäo, magia e positivismo na República Rio-Grandense-1889-1928”. En Medicina, religiäo, magia e positivismo na República Rio-Grandense-1889-1928.

Yangilevich, M. 2007. Estado y criminalidad en la frontera sur de Buenos Aires (1850-1880). Rosario, Prohistoria.

\section{Documentación}

Archivo Histórico Provincial Ricardo Levene, Departamento Judicial de la Capital Juzgado del Crimen. (AHPRL/DJC/JC): 
- Apelación de Juan Francisco Halbout contra un fallo del Juez de paz de Quilmes sobre condena por ejercicio ilegal de la medicina. (1876). Quilmes. Exp. 38-333/16/1876.

- Proceso seguido por práctica indebida de la medicina contra Vicente Tagle. (1880), San Vicente. Exp. 40-1/352/11/1880

- Sumario levantado con motivo de denuncia por práctica de un aborto a una niña contra Vicente Tagle. (1880), San Vicente. Exp. 40$1 / 355 / 2 / 1880$.

Hemeroteca de la Facultad de Ciencias Médicas de la Universidad de Buenos Aires (HFCMUBA):

- Anales del Departamento Nacional de Higiene, 1902:754-756.

Archivo Histórico Municipal de Tandil (AHMT):

- Libro Copiador del Juez de Paz de 1871.

- Registro Oficial 1877: Ley provincial 1110/1877

Museo Histórico Fuerte Independencia (Tandil):

- Sumario levantado durante la investigación de los asesinatos del 1 de enero de 1872. 